\title{
A análise linguística e o texto \\ dissertativo-argumentativo: um olhar sobre o ensino \\ de língua portuguesa
}

\author{
Linguistic analysis and \\ dissertative-argumentative texts: a look at the \\ teaching of portuguese
}

\author{
Marina Zvierzikovski Marchioro
}

\begin{abstract}
Resumo: O objetivo central deste trabalho é apresentar sugestões de atividades relacionadas com o texto dissertativo-argumentativo, tendo por foco a análise linguística, com base nos pressupostos teóricos fornecidos pela concepção sociointeracionista da linguagem. Primeiramente, fizemos uma retrospectiva histórica da disciplina de Língua Portuguesa; em seguida, discorremos sobre o ensino pautado em gêneros discursivos, tendo como embasamento as Diretrizes Curriculares da Educação do Estado do Paraná e os autores Luiz Antonio Marcuschi, Irandé Antunes e Maria Aparecida Garcia Lopes-Rossi. Num terceiro momento, apresentamos as atividades propostas para alunos de $3^{\circ}$ ano do Ensino Médio, bem como os resultados obtidos na aplicação das atividades desenvolvidas.

Palavras-chave: Gêneros discursivos. Análise linguística. Texto dissertativo-argumentativo.

Abstract: The main goal of this paper is to present suggestions of activities for the teaching of dissertative-argumentative texts focusing on linguistic analysis. The analysis is supported by the socio-interactionist conception of language. In order to do so, a historical survey about the teaching of Portuguese is presented as well as a discussion about the teaching of the discursive genres, based on Educational Curricular Guidelines of Paraná State and authors such as Luiz Antonio Marcuschi, Irandé Antunes and Maria Aparecida Garcia Lopes-Rossi. The paper presents the activities designed for students of the third grade of high school and also the outcomes of the activities.
\end{abstract}

Keywords: Discursive Genres. Linguistic analysis. Dissertative-Argumentative texts.

\section{Introdução}

Este artigo pretende apresentar uma proposta pedagógica relacionada com o texto dissertativo-argumentativo, tendo como foco a análise linguística

* Especialista Universidade Estadual do Centro Oeste-UNICENTRO. E-mail: nina_kovski@yahoo.com.br. 
desenvolvida à luz da concepção sociointeracionista da linguagem. Nesta perspectiva, procuramos fazer uma retrospectiva histórica da disciplina de Língua Portuguesa; identificar as características e os elementos que compõem o texto dissertativo-argumentativo; refletir sobre o ensino de gramática à luz do sociointeracionismo; e apresentar sugestões de atividades de análise linguística em relação ao tipo de texto já referido.

A importância do trabalho com o texto dissertativo-argumentativo não se restringe ao vestibular. Em uma classe do $3^{\circ}$ ano do Ensino Médio, são poucos os que tentam ingressar e poucos os que conseguem adentrar ao ensino superior, por isso, o ensino de Língua Portuguesa não pode ter objetivos limitados a um pequeno número de educandos, necessitando de amplitude em seu planejamento. Além disso, com a produção dissertativo-argumentativa, o aluno tem a possibilidade de apresentar seu ponto de vista em relação a temas sociais, bem como refletir e argumentar sobre ele, pois, por intermédio do texto, o aluno marca o seu espaço. É a partir destas considerações que se justifica o presente trabalho.

Segundo as Diretrizes Curriculares de Língua Portuguesa para Educação Básica do Estado do Paraná (DCE, PARANÁ, 2008), desde que o ensino de Língua Portuguesa se tornou obrigatório no Brasil, já se considerava a língua como sistema e o ensino era voltado para as classes ditas privilegiadas. Com o decreto imperial de 1871, o conteúdo gramatical foi denominado Português e ser professor de Português foi considerado um cargo. A norma padrão nesta época era a única em voga em sala de aula.

Já no século XX, no decorrer da década de 60 , com a democratização do ensino, o número de alunos aumentou significativamente a partir do acesso à educação de pessoas de diferentes grupos sociais. A escola, que não soube lidar com outras variações linguísticas, viu-se obrigada a aumentar o número de professores por meio de cursos rápidos de formação. Surge, para isso, o livro didático que, enfatizando o ensino gramatical, pretende solucionar o despreparo dos professores.

Na década de 70, com o processo de industrialização, a educação desenvolveu uma pedagogia tecnicista, que visava à qualificação para o mercado de trabalho. O ensino passa a ser centrado na teoria da comunicação, ou seja, a linguagem é vista como instrumento de comunicação e a metodologia está pautada em exercícios estruturais, técnicas de redação e treinamento de habilidade de leitura. Com isso, o livro didático passou a ser produzido 
industrialmente, porém o professor perdeu a autonomia e a responsabilidade no que se referia à prática, ocasionando, segundo as DCEs (PARANÁ, 2008), a aplicação de exercícios estruturais, que desconsideravam a interação com o texto e a expansão dos sentidos da leitura. Contudo, a concepção assumida pela lei 5.692/71, que considerava a linguagem como instrumento de comunicação, sofreu críticas, ou porque os professores estavam insatisfeitos com os resultados ou porque queriam voltar ao ensino tradicional.

Após os anos 80, as ideias do Círculo de Bakhtin chegam ao ensino brasileiro, mobilizando os professores para discutirem e a repensarem o trabalho de ensino de Língua Portuguesa, embasados em textos dos linguistas Carlos Alberto Faraco, Sírio Possenti e João Wanderley Geraldi. Nessa perspectiva, a língua é vista como forma de interação entre sujeitos, os quais se constituem por intermédio dessa interação.

É no final dos anos 80 e começo dos anos 90 que teorias como a Análise do Discurso, Sociolingüística e Linguística Textual entram no ensino, abrindo novos horizontes para o processo ensino/aprendizagem da língua materna. A partir de 1998, com os Parâmetros Curriculares Nacionais (PCN, BRASIL, 1998), o texto passa a ser o centro do ensino.

Com a amplitude das relações sociais, bem como a grande variedade de textos, é importantíssimo que o ensino de Língua Portuguesa gire em torno do texto e busque maior eficácia na ampliação das competências linguísticas, textuais e comunicativas do indivíduo. Foi nos anos 90, com a discussão sobre um ensino favorável para o desenvolvimento destas competências, que se recuperou o conceito de gênero discursivo de Bakhtin, o qual, segundo Lopes-Rossi (2002, p. 25), considerava os gêneros como "formas típicas de enunciados [...] que se realizam em condições e com finalidade específicas nas diferentes situações de interação social." Nessa mesma época, surge a expressão "produção de textos". E assim, muda-se o foco do ensino: a língua deixou de ser vista apenas como estrutura e voltou-se para o contexto de produção e recepção dos textos.

\section{Fundamentação teórica}

Após diversas pesquisas, busca-se hoje, no ensino de Língua Portuguesa, uma inter-relação entre atividades de oralidade, leitura, produção textual e 
análise linguística, tendo por objetivo ajudar ao aluno a obter domínio dessas práticas discursivas para, desta forma, realizar a proposta apresentada pelas DCEs (2007, p. 33) de "formar usuários competentes da língua, de modo que, pela fala, escrita e leitura, exercitem a linguagem de forma consistente e flexível, adaptando-se a diferentes situações de uso."

Segundo Lopes-Rossi (2002, p. 29), o desenvolvimento da competência comunicativa é imprescindível para que o aluno aja como sujeito ativo em suas produções textuais e, para tanto, a competência comunicativa “[...] deve incluir, além de conhecimentos linguísticos referentes ao léxico e à estrutura da língua, também conhecimentos específicos a respeito dos diferentes gêneros discursivos."

Hoje o trabalho em Língua Portuguesa está fortemente pautado nos gêneros discursivos e, propriamente, toda prática discursiva é norteada por gêneros. Porém, conhecer diferentes gêneros não acarreta conhecer todos eles. A escolha, portanto, deve ser orientada pelas necessidades, objetivos e faixa etária dos alunos, como também por aqueles gêneros que despertam seu interesse; desta forma, aumentarão a capacidade comunicativa e o desenvolvimento das habilidades de leitura e produção.

Segundo Irandé Antunes (2003, p. 41), “somente uma concepção interacionista da linguagem, eminentemente funcional e contextualizada, pode, de forma ampla e legítima, fundamentar um ensino da língua que seja individual e socialmente produtivo e relevante." Também considera que o objeto do ensino deve ser o estudo das regularidades textuais e discursivas, na sua produção e interpretação.

Lopes-Rossi (2002, p. 28) enfatiza que o aluno deve conhecer as condições de produção e de circulação, bem como as características típicas do gênero abordado, para agir como um sujeito ativo na produção de textos, ao observar a adequação do vocabulário, a utilização dos recursos linguísticos e a escolha de informações adequadas ao propósito do texto.

Cabe ao professor, segundo a autora, a percepção das necessidades e possibilidades de produção de determinados gêneros na sala de aula, considerando o texto verbal e não-verbal constituintes dos gêneros discursivos, permitindo ao aluno interpretar os diferentes textos que circulam na sociedade e promovendo um ensino mais eficaz para a produção textual. Esta requer etapas distintas, exigindo a elaboração de um planejamento de atividades para 
alcançar o objetivo final, o texto. As etapas se dividem em: leitura do gênero; organização dos alunos para a produção escrita; planejamento para se obter informações necessárias; escrita da primeira versão; reescrita e versão final.

Na etapa de reescrita, segundo as DCEs (PARANÁ, 2008, p. 44), o professor planeja e desenvolve atividades de reflexão com os alunos sobre sua produção textual. As atividades podem ser de: revisão, reestruturação, refacção, análise em grupo de vários gêneros. É na etapa de reescrita que se podem realizar atividades de análise linguística, partindo das dificuldades dos alunos, constatadas na escrita do gênero escolhido. João Wanderley Geraldi, em seu livro $O$ texto na sala de aula, cuja primeira publicação é de 1984, sugere "a prática de análise linguística":

O uso da expressão "prática de análise linguística" não se deve ao mero gosto por novas terminologias. A análise linguística inclui tanto o trabalho sobre questões tradicionais da gramática, quanto de questões amplas a propósito do texto [...]. Essencialmente, a prática da análise linguística não poderá limitar-se à higienização do texto do aluno em seus aspectos gramaticais e ortográficos, limitando-se a "correções". Trata-se de trabalhar com o aluno o seu texto para que ele atinja seus objetivos junto aos leitores a que se destina. (GERALDI, 1997, p. 74, grifos do autor).

Com isso, tem-se uma nova visão para o processo de ensino-aprendizagem de Língua Portuguesa, partindo da produção do aluno para o ensino gramatical.

O ensino de língua pautado no texto é alvo de reflexões há tempo, no entanto, verifica-se maior ênfase na leitura e produção, deixando-se de lado a análise linguística. Se considerarmos que "não existe língua sem gramática" (ANTUNES, 2003, p. 85), não se pode abandonar o ensino de gramática e menos ainda ensiná-la de forma apenas normativista, abordando regras e nomenclaturas, pois as questões gramaticais devem ser vistas de forma reflexiva, levando o aluno a observar e analisar a língua em uso.

O aluno deve aprender sobre a língua e aplicá-la na vida, não apenas ser alfabetizado, mas letrado. Quando chega à sala de aula, o aluno já possui a "gramática internalizada" (TRAVAGLIA, 2001, p. 29), contudo, ao final do ano letivo, aquilo que ele considera como língua precisa estar modificado, ampliado, senão o ensino de língua materna não teria objetivo. 
O ensino deve possibilitar ao estudante a apropriação do conhecimento linguístico a fim de que ele o utilize em situações concretas. Sendo assim, o aluno precisa avançar significativamente e reconhecer, por exemplo, as regularidades e irregularidades nas normas ortográficas, como também escrever e reescrever a sua produção textual, interagindo com o texto, com os colegas e com o professor, observando as características discursivas e linguísticas do gênero escolhido. Neste caso, o aluno terá condições de compreender como a língua funciona, como é organizada em textos, como elementos gramaticais servem para ligar palavras, frases, parágrafos, exercitando, dessa forma, a linguagem em diferentes contextos.

Travaglia (2001) propõe algumas sugestões de ensino de gramática almejando desenvolver a competência comunicativa dos alunos de forma que adquiram novas habilidades linguísticas. $\mathrm{O}$ autor aborda as concepções básicas de gramática: a normativa, que estipula regras para falar e escrever "bem"; a descritiva, que considera o funcionamento da língua dentro de uma variedade linguística; e a internalizada, correspondente ao conhecimento adquirido pelo falante fora da escola. Para o autor, a concepção de linguagem como interação recebeu contribuições teóricas principalmente da Linguística da Enunciação.

Considerar a linguagem como forma de interação é reconhecer que os falantes atuam como sujeitos e o diálogo passa a ser caracterizador da linguagem. Quando se trata de análise linguística, o sujeito reflete, dialoga com o texto e com alguém, analisando os recursos lexicais e gramaticais contidos no contexto de produção textual.

Sobre isso, Antunes (2003, p. 45) observa que:

Uma visão interacionista da escrita supõe, desse modo, encontro, parceria, envolvimento entre sujeitos, para que aconteça a comunhão das ideias, das informações e das intenções pretendidas. Assim, por essa visão se supõe que alguém selecionou alguma coisa a ser dita $a$ um outro alguém, com quem pretendeu interagir, em vista de algum objetivo. (grifos da autora).

Pode-se conceber, então, que os gêneros discursivos não são apenas perspectivas ou conceitos, mas uma prática social, considerada pelas DCEs (PARANÁ, 2008, p. 19) "como toda atividade humana exercida com e na linguagem". A competência linguística do aluno se aprimorará com os gêneros discursivos, desde que perceba que a linguagem não se restringe às práticas 
escolares, mas tem a ver com a sociedade da qual ele faz parte. Assim será capaz de pensar e produzir seu discurso próprio, de modo que seja um sujeito que interfere na sua sociedade. Pois é na escola que "o estudante brasileiro tem a oportunidade de aprimoramento de sua competência linguística, de forma a garantir uma inserção ativa e crítica na sociedade." (PARANÁ, 2008, p. 4).

Quando o aluno for movido a pensar a sua sociedade de maneira crítica, ele conseguirá se envolver com os textos que produz e assumir sua autoria, tornando-se "um sujeito que tem o que dizer, quando escreve, ele diz de si, de sua leitura do mundo." (PARANÁ, 2008, p. 22). Para que se produza uma leitura de mundo eficaz, é de grande relevância o estímulo do pensamento crítico no aluno, ou seja, levá-lo a perceber a realidade que o rodeia e analisá-la, interpretá-la por meio da linguagem.

Considerando que a linguagem se materializa no texto, é nele que se percebe a visão crítica do aluno, uma vez que "todo texto é, assim, articulação de discursos, vozes que se materializam, ato humano, é linguagem em uso efetivo" (PARANÁ, 2008, p. 17). Logo, o ensino de Língua Portuguesa precisa estimular o "pensar crítico" sobre a realidade, e nesse contexto se insere o trabalho com gêneros discursivos, principalmente os que estimulam e levam o aluno mais próximo da sociedade em que está inserido, porque "pensar é inerente à natureza humana" (SILVA, 2002, p. 48). Evidentemente, não se pode ensinar alguém a pensar, mas sim "incentivar o diálogo, criar oportunidades para que os alunos discutam ideias, apresentem suas razões, examinem os critérios utilizados, promovam o exercício de autocorreção, com a finalidade de fazer valer, de forma inteligente e crítica, sua voz no mundo". (Ibidem).

O texto dissertativo-argumentativo tem como principal característica expor um ponto de vista, defender uma ideia, questionar um assunto, como também analisar algum tema com argumentos que viabilizem determinado ponto de vista. Ou seja, é pautado na argumentação. Segundo Lopes-Rossi (2002, p.137), no cotidiano é necessário argumentar, e isto acontece em vários gêneros, e o que os identifica são as características textuais, as condições de produção e circulação específica.

Para Elisabeth Ramos da Silva (2000, p. 19) a produção de texto, sobretudo os de cunho argumentativo, serve para desenvolver o pensamento crítico nos alunos, como também proporcionar-lhes subsídios que contribuam para a formação cultural. 
Até hoje, os teóricos não chegaram a um consenso se o texto dissertativo-argumentativo é um tipo ou um gênero. Pode ser um tipo, visto, segundo Marcuschi (2007, p. 22), como "uma espécie de sequência teoricamente definida pela natureza linguística de sua composição \{aspectos lexicais, sintáticos, tempos verbais, relações lógicas\}". Por outro lado, pode ser considerado um gênero, pois, segundo o mesmo autor, gêneros são "ações sócio-discursivas para agir sobre o mundo e dizer o mundo, constituindo-o de algum modo", e, ainda, "gêneros são formas verbais de ação social relativamente estáveis realizada em textos situados em comunidade de prática sociais em domínios discursivos específicos".

Segundo José Luiz Fiorin (2007. p. 101), Bakhtin em sua teoria não considerava o produto e sim o processo de produção do gênero. Com isso, avaliar qualquer produção textual como tipo ou gênero não depende apenas do produto final realizado pelo aluno, mas de todo o processo que acarretou a produção. Por isso, o texto dissertativo-argumentativo pode ser um gênero porque, ao se analisar o processo de produção, percebe-se que o referido texto possui todas as condições que Bakhtin atribuía a um gênero.

A utilização da língua efetua-se em forma de enunciados (orais e escritos), concretos e únicos, que emanam dos integrantes duma ou doutra esfera da atividade humana. $\mathrm{O}$ enunciado reflete as condições específicas e as finalidades de cada uma dessas esferas, não só por seu conteúdo (temático) e por seu estilo verbal, ou seja, pela seleção operada nos recursos da língua - recursos lexicais, fraseológicos e gramaticais -, mas também sobretudo por sua construção composicional. (BAKHTIN, 1997, p. 279).

Bakhtin também apontava que os elementos: conteúdo temático, estilo e construção composicional constituem-se no todo do enunciado, e a esfera de comunicação em que está inserido é que marca o gênero.

O texto dissertativo-argumentativo possui essas condições. A esfera de comunicação é a própria escola, pois é nela que se busca aprimorar o conhecimento de mundo, bem como o desenvolvimento crítico sobre ele. Segundo Fiorin (2007, p. 101), os gêneros estabelecem "uma interconexão da linguagem com a vida social. A linguagem penetra na vida por meio dos enunciados concretos, e ao mesmo tempo, por eles a vida introduz-se na linguagem". Ou seja, a vida social e os acontecimentos no mundo têm que fazer parte do ensino de Língua Portuguesa. 
O conteúdo temático do texto dissertativo-argumentativo está relacionado intrinsecamente com os acontecimentos sociais, ou seja, temas amplos, sobre os quais o aluno reflete e em relação aos quais se percebe como um cidadão. O estilo é argumentativo, pois através dos argumentos o aluno "age por meios discursivos provocando uma ação sobre o que se pretende modificar" (AQUINO, 2002, p. 76), e os conectivos, palavras próprias para correlacionar e para unir frases, parágrafos e ideias, introduzem esses argumentos e podem causar efeito de oposição, alternância, explicação, causa, consequência, concessão, inclusão e conclusão. $\mathrm{O}$ efeito que se pretende fica na dependência da escolha e emprego adequados deste ou daquele conectivo.

A construção composicional se define pela apresentação temática na introdução; a exposição do ponto de vista, sustentado por argumentos, está no desenvolvimento; e o posicionamento do escritor do texto, de forma indireta, no item conclusão. É na introdução que se apresenta o assunto, a ideia central e o ponto de vista. No desenvolvimento está a análise crítica da ideia central, podendo ser em vários parágrafos, nos quais se apresentam os argumentos que sustentam a referida ideia central. É na conclusão que o aluno reafirma seu posicionamento sobre o assunto. Além disso, no título já se condensa a posição em relação ao assunto.

Diante disso, consideramos que o texto dissertativo-argumentativo estimula, no aluno, o desenvolvimento do pensamento crítico em relação a temas reais, que fazem parte de sua sociedade. É importante realçar o trabalho de mediação do professor, orientando os alunos na escolha de argumentos que sejam plausíveis. Hoje, com "bombardeio" de informações, "torna-se necessário formar alunos com capacidade crítica, a fim de que possam discriminar os problemas, estabelecer valores e efetuar escolhas sensatas". (SILVA, 2002, p. 52).

Ilustrando a assertiva, no vestibular da UNICENTRO cobra-se o texto dissertativo-argumentativo, evidenciando que o contexto do ensino criou o gênero dissertativo-argumentativo. Nesse âmbito, se faz necessário pensar numa proposta pedagógica pautada neste gênero, principalmente quando se refere ao $3^{\circ}$ ano do Ensino Médio, pois os alunos, após o final do ano letivo, entram no mercado de trabalho, na universidade e em outros lugares que exigem deles que tenham um ponto de vista, para não serem considerados jovens alienados e para serem realmente cidadãos. 
Assim sendo, cabe também à escola "preparar o educando para o exercício da cidadania. Afinal, uma sociedade democrata pressupõe a existência de cidadãos livres, autônomos, capazes de julgar e escolher os caminhos que deverão ser trilhados pela nação." (Ibidem, 2000, p. 27).

\section{Considerações finais}

Segundo Bakhtin (PARANÁ, 2007, p. 16), é pela linguagem que o homem se reconhece como humano, por meio dela o sujeito interage e compreende a realidade na qual está inserido e assume seu papel como membro da sociedade. Por isso se faz tão necessária a reflexão com e sobre a língua. É papel do professor criar possibilidades para que o aluno perceba a multiplicidade de usos e funções da língua, a fim de que possa ser um usuário competente da língua, exercitando e adaptando a linguagem em diferentes situações de uso, por meio dos gêneros discursivos.

O ensino de Língua Portuguesa precisa ser trabalhado de forma ampla, não apenas para enfocar a leitura e produção de textos, mas também considerando a análise linguística, para que o aluno desenvolva essas práticas discursivas. Assim, faz-se necessário um (re)pensar sobre o processo de ensino-aprendizagem de língua materna, já que a interação entre os sujeitos é de grande relevância no processo.

Para Geraldi (1997, p. 74), "o objetivo essencial da análise linguística é a reescrita do texto do aluno". Não devemos enfocar terminologias, mas buscar a compreensão do fenômeno linguístico. Em textos com caráter argumentativo, é interessante que o aluno analise a clareza, a objetividade e a fidelidade em relação ao que se escreve.

No estágio supervisionado, verificamos a melhora no desenvolvimento da habilidade da escrita. Se compararmos a primeira versão com a segunda (a reescrita) observaremos o crescimento linguístico do aluno após as atividades de análise linguística, bem como a passagem pelas etapas de produção referidas por Lopes-Rossi.

Como este artigo se apresenta como uma sugestão, consideramos que é difícil cumprir todas as etapas de produção e realizar atividades de análise linguística em salas com número elevado de alunos. Além disso, para 
o professor, devido às condições de trabalho, será mais complicado trabalhar a escrita e a reescrita de textos. Mas, percebemos que não é impossível, pois,

Se formos capazes de criar condições que induzam nossos alunos a pensar, estaremos contribuindo para a formação do cidadão participante, do indivíduo autônomo e humanitário, de um ser com maiores probabilidades de conhecer-se a si mesmo e de perceber a responsabilidade de sua atuação no mundo. A compreensão da realidade, a capacidade de tecer julgamentos equânimes é a condição que liberta os homens dos preconceitos, dos impulsos passionais, egoístas, injustos e discriminatórios. (SILVA, 2000, p. 32).

Os profissionais do ensino não devem "pensar para quem vão ensinar" e sim "para que vão ensinar”, então, com esforços conjuntos construir-se-á “A escola dos sonhos" de Rubem Alves.

\section{Referências}

ALVES, Rubem. A escola dos meus sonhos. In: ALEXANDRE, Rosane Aparecida. Revista Educação. São Paulo: Editora Segmento, Ano 7, n.76. ago. 2003.

AMARAL, Emilia; FERREIRA, Mauro; LEITE, Ricardo; ANTONIO, Severino. Novas palavras. 2. ed. (renovada) São Paulo: FTD, 2005 (Coleção Novas Palavras).

ANTUNES, Irandé. Muito além da gramática: por um ensino de línguas sem pedras no caminho. São Paulo: Parábola Editorial, 2007. (Série Estratégias de Ensino; 5).

(Série Aula; 1).

Aula de português: encontro e interação. São Paulo: Parábola Editorial, 2003.

AQUINO, Zilda G. Oliveira. O espaço da argumentação no ensino da língua materna. In: SILVA, Elisabeth Ramos da Silva (Org.). Texto e ensino. Taubaté-SP: Cabral Editora, 2002.

BAKHTIN, Mikhail. Estética da criação verbal. São Paulo: Martins Fontes, 1997.

. Marxismo e filosofia da linguagem. São Paulo: Hucitec, 1986.

BUNZEN, Clecio. Da era da composição à era dos gêneros: o ensino de produção de texto no ensino médio. In: MENDONÇA, Márcia; BUNZEN, Clecio. (Org.). Português no ensino médio e formação do professor. São Paulo: Parábola. 2006. (Série Estratégias de ensino, 2).

CEREJA, Willian Roberto; MAGALHÃES, Thereza Cochar. Texto e interação: uma proposta de produção textual a partir de gêneros e projetos. São Paulo: Atual, 2005.

FIORIN, José Luiz. O ensino de português nos níveis fundamental e médio: problemas 
e desafios. In: SCHOLZE, L.; RÖSING, Tania M. K. Teoria e prática de letramento. Brasília-DF: INEP - UPF, 2007.

GERALDI, João Wanderley. Unidades básicas do ensino de português. In: O texto na sala de aula. São Paulo: Ática, 1997.

KLEIMAN, Ângela. Leitura e prática social no desenvolvimento de competências no ensino médio. In: MENDONÇA, Márcia; BUNZEN, Clecio. (Org.). Português no ensino médio e formação do professor. São Paulo: Parábola. 2006. (Série Estratégias de ensino, 2).

LOPES-ROSSI, Maria Aparecida Garcia. O desenvolvimento de habilidades de leitura e de produção de textos a partir de gêneros discursivos. In: . (Org.). Gêneros discursivos no ensino de leitura e produção de textos. Taubaté-SP: Cabral, 2002.

. A produção de texto escrito na escola a partir de gêneros discursivos. In: SILVA, Elisabeth Ramos da Silva. Texto e ensino. Taubaté-SP: Cabral Editora, 2002.

MARCUSCHI, Luiz Antonio. Gêneros textuais: definição e funcionalidade. In: DIONISIO, Angela Paiva; MACHADO, Anna Rachel; BEZERRA, Maria Auxiliadora. Gêneros textuais e ensino. 5. ed. Rio de Janeiro: Lucerna, 2007. p.19-36.

ORLANDI, Eni P. Análise de discurso: princípios e procedimentos. 6. ed. Campinas: Pontes, 2005.

PARANÁ, Secretaria de Estado da Educação. Diretrizes curriculares de língua portuguesa para Educação Básica. Curitiba: SEED, 2007 - 2008.

POSITIVO, Sociedade Educacional. Redação: conhecimento, conquista, liberdade. (apostila). Curitiba: Editora Positivo 1994.

SILVA, Elisabeth Ramos da. O desenvolvimento do pensar crítico no ensino da língua materna: um objetivo de natureza transdisciplinar. In: .Texto e ensino. Taubaté-SP: Cabral Editora, 2002.

O ponto de partida da argumentação: o desenvolvimento do senso crítico. Taubaté-SP: Cabral Editora, 2000.

TRAVAGLIA, Luiz Carlos. Gramática e Interação: uma proposta para o ensino de gramática no $1^{\circ}$ e $2^{\circ}$ graus. 7. ed. São Paulo: Cortez, 2001.

VAL, Maria da Graça Costa. Interação linguística como objeto de ensino/aprendizagem da Língua Portuguesa. Jornal da Alfabetizadora. Ano VI, n. 32.

UNICENTRO, Universidade Estadual do Centro-Oeste. Vestibular 2007. Disponível em: $<\mathrm{http}$ ://www.unicentro.br/vestibular/provasanteriores/provas20072.pdf $>$. Acesso em: 31 mar. 2008.

Recebido para publicação em 01 jul. 2010

Aceito para publicação em 16 jul. 2010 


\section{Anexo}

\section{Proposta pedagógica}

Este trabalho é fruto das práticas de leitura e escrita realizadas durante a fase de Estágio Supervisionado num colégio estadual de Guarapuava, PR, no ano de 2008. O corpus também se apresenta como suporte para a proposta de trabalho com análise linguística a partir das produções de textos dos alunos do $3^{\circ}$ ano do Ensino Médio.

Primeiramente, descrevemos as atividades realizadas para que se chegasse à produção.

Atividade 1: Banca do absurdo. (AMARAL, 2005, p. 263).

Objetivo: Motivar o desenvolvimento da capacidade argumentativa.

Comando: Agora vamos fazer uma dinâmica que nos ajudará no desenvolvimento de argumentos, pois esses são de grande importância para expressarmos nossas ideias e realizarmos a defesa delas sobre o assunto.

Você e seus colegas de grupo tentarão vender aos seus colegas da classe determinado produto, expondo a importância desse produto na vida, qual a sua utilidade, o seu valor ...

Grupo 1: Palito de fósforo queimado.

Grupo 2: A Catedral de nossa cidade.

Grupo 3: Um terreno na Lua.

Grupo 4: Uma escova de dente usada.

Grupo 5: Um jornal velho e rasgado.

Grupo 6: Uma caneta que não escreve.

Após a dinâmica, orientamos a classe a refletir sobre: "Qual produto vocês comprariam?" Nesta dinâmica pudemos observar o poder de persuasão dos argumentos e verificar que a argumentação está presente no cotidiano. 
Atividade 2: Várias leituras: um olhar sobre a sociedade.

Objetivos: Estimular a competência investigativa e compreensiva e também desenvolver a prática da oralidade.

Comando: Você vai pesquisar um texto de seu interesse, pode ser de jornal, revista, Internet. Ao ler o texto, observe o assunto que ele aborda, onde você o encontrou, por que ele chamou sua atenção. Formule o seu ponto de vista em relação a esse assunto. Depois, de maneira sucinta, você vai apresentá-lo aos colegas.

No segundo momento, procuramos refletir com os alunos sobre o texto "Chega-se a Marte, mas não se chega ao próximo" (In: AMARAL, 2005, p. 242 ), procurando identificar o tema, o ponto de vista e o argumento no texto.

Atividade 3: "Chega-se a Marte, mas não se chega ao próximo."

"Neste meio século não parece que os governos tenham feito pelos direitos humanos tudo aquilo a que moralmente estavam obrigados. As injustiças multiplicam-se, as desigualdades agravam-se, a ignorância cresce, a miséria alastra. A mesma esquizofrênica humanidade capaz de enviar instrumentos a um planeta para estudar a composição das suas rochas assiste indiferente à morte de milhões de pessoas pela fome. Chega-se mais facilmente a Marte do que ao nosso próprio semelhante."

(Trecho do discurso de José Saramago ao receber o Prêmio Nobel de Literatura. In: Folha de S. Paulo, 11/12/1998).

Para refletir:

Qual é o tema deste trecho?

Qual o ponto de vista?

Que argumento(s) é (são) utilizado(s)?

Posteriormente, foi apresentado aos alunos um exemplo de texto dissertativo-argumentativo da apostila Positivo (POSITIVO, 1994), com o objetivo de o aluno observar a estrutura e os recursos linguísticos.

Exemplo1: Um planeta que pede socorro. 


\section{(Introdução)}

Está em evidência a destruição do nosso planeta, principalmente, devido à poluição do meio ambiente, que é uma realidade difícil de ser controlada. E também porque são inúmeros os conflitos internacionais, bem como o manuseio de armas químicas entre os exércitos.

\section{(Desenvolvimento)}

O ecossistema, por ser muito frágil, é o principal atingido pela poluição, tanto visível, como a que sai dos carros e fábricas, quanto a poluição que não se pode ver ou sentir, como as irradiações, que interferem no metabolismo humano ou animal sem que esses as percebam ou possam evitá-las.

Outras formas de destruição são os riscos oferecidos pelas possíveis guerras entre as mais diversas nações, que, além de depredarem o espaço físico, podem causar, no futuro, danos irreversíveis à população, à fauna e à flora; sem falar dos transtornos psicológicos e emocionais que acarretam.

\section{(Conclusão)}

Diante dos fatos mencionados, pode-se afirmar que, mesmo sendo tomadas atitudes positivas e favoráveis ao planeta, ele está muito longe de "respirar" aliviado, pois faltam ainda consciência e sensibilidade por parte daqueles que mais dependem desse para a sobrevivência: os seres humanos.

Depois disso, utilizando o recurso pedagógico Tv Multimídia, que possui entrada USB para uso do pen drive, refletimos com aos alunos sobre as características do texto dissertativo-argumentativo (Texto A) e quais os modos de se construir o desenvolvimento (Texto B).

Texto A - Principais características: temática; texto que analisa e interpreta; aponta relações lógicas e na maioria das vezes possui verbos no presente. 
Texto B - Geralmente cada argumento corresponde a um parágrafo. Agora veremos os modos mais comuns de construção do desenvolvimento do texto dissertativo-argumentativo. Eles são organizados com base em: enumeração, exemplificação, comparação e contraste, definição, alusão histórica, causa e consequência, e citação.

Em seguida foram trabalhadas dicas de como se produzir um texto dissertativo-argumentativo (Texto C) e sugestões de como produzi-lo (Texto D).

Texto C: Dicas para a produção do texto dissertativo-argumentativo. Estas dicas foram elaboradas a partir de sugestões do site http://cpv.com.br.

Valorize sempre toda leitura informativa.

Use um rascunho, pois ele é fundamental.

Reflita sobre os textos de apoio e o comando da produção para que não fuja ao tema.

Faça letra legível, sem rasuras e erros ortográficos.

Evite marcas da oralidade e repetição de palavras, bem como gírias e estrangeirismos (que só podem aparecer entre aspas). textual.

Evite chavões, clichês, prolixidade, para não comprometer a concisão

Não faça cópia de revistas ou jornais, para não destruir a originalidade e criatividade de seu texto.

Não use informações falsas nem dados estatísticos sem absoluta certeza da veracidade dos mesmos.

Nunca passe a limpo sem antes ler o rascunho para corrigir erros, problemas de pontuação ou palavras repetidas.

Texto D: Sugestão de como produzir um texto dissertativo-argumentativo:

(Atividade desenvolvida com base no texto de CEREJA, 2005).

A partir do tema proposto, reflita sobre qual é o seu posicionamento em relação a ele.

Anote os argumentos para fundamentar o ponto de vista que você 
pretende desenvolver.

Pense na introdução que gostaria de desenvolver.

De acordo com o que você pretende defender ou provar, selecione os argumentos que melhor possam fundamentá-lo e pense nas formas mais adequadas para desenvolver os argumentos que você selecionou: exemplificação, comparação, causa e consequência, etc. Esboce os parágrafos de desenvolvimento e o conteúdo de cada um deles.

Pense na melhor forma de concluir seu texto: retomando com outras palavras o que foi exposto ou confirmando a ideia principal que você defende.

f) Observe a coesão entre as partes. Para isso, lembre-se de empregar palavras e expressões que garantam a conexão do texto, como: apesar disso, além disso, por outro lado, contudo, outro aspecto a destacar, cabe ressaltar ainda, etc.

Busque uma linguagem sóbria, objetiva, tendendo à impessoalidade, com vocabulário rico e preciso, e de acordo com a variedade padrão.

Tenha em vista que o leitor final de seu texto serão seus colegas.

Dê ao texto um título criativo, que desperte a curiosidade do leitor.

Quando concluir seu texto, revise-o e faça alterações necessárias. Passe-o a limpo.

Depois, a partir de temas pedidos em vestibulares da UNICENTRO, foi distribuída a proposta de produção textual (Texto E) aos alunos, a qual possibilitou a eles a escolha de um tema entre três, conforme os procedimentos próprios dos vestibulares da instituição. A produção teve por objetivo estimular o desenvolvimento do pensamento crítico sobre temas sociais. Neste caso, os colegas da classe foram os interlocutores.

Texto E: Produção Textual (UNICENTRO 2007)

\section{Os miseráveis}

No Brasil a pobreza foi se acumulando em camadas sedimentares ao longo de muitos anos de estagnação ou desenvolvimento. O desenvolvimento destrói formas antigas de produção. A estagnação impede que novas gerações se incluam na economia maior e renovada. 
Na primeira camada, está o Brasil profundo - índios e caboclos que vivem da floresta, caiçaras pescadores em praias inacessíveis, sertanejos do Nordeste árido. O capitalismo passou ao largo dessas famílias pobres de vida franciscana, que, a bem da verdade, deveriam ser deixadas em paz.

Sobre essa está a camada dos brasileiros pobres expulsos pelo desenvolvimento agrícola ou atraídos pelas cidades iluminadas e cheias de empregos, que saíram de onde estavam, procurando novas oportunidades, e encontraram crises financeiras em vez de empregos. Acumularam-se na periferia das grandes cidades, em favelas, cortiços e invasões.

Uma terceira camada se deposita sobre as outras duas, a das famílias que haviam chegado ao emprego da cidade e que constituíam a classe média baixa ou operários com emprego fixo, muitos com carteira assinada. Perderam o emprego, o lugar que tinham e foram morar em habitações precárias [...].

A pobreza pode ser apenas aliviada pelos gastos sociais e pela ação benemérita do terceiro setor. Só o crescimento pode evitar que os jovens que chegam à idade de trabalhar não consigam emprego e acabem se amontoando entre os pobres. Já perdemos duas gerações, excluídas pela estagnação. A pobreza é um fenômeno monetário.

(SAYAD, João. Os miseráveis. Folha de S. Paulo. São Paulo. Cad. Opinião, A2-27, set. 2004).

O texto acima apresenta o ponto de vista do economista João Sayad sobre a pobreza no Brasil. Baseado nas ideias nele contidas redija um texto dissertativo-argumentativo sobre o que você pensa a respeito do problema da pobreza.

\section{SUGESTÕES:}

Discuta a questão da pobreza no Brasil como um problema inalterado. Argumente no sentido de demonstrar que conhece a realidade retratada. Explore ideias que destaquem as causas e consequências dessa realidade,

propondo soluções viáveis. (UNICENTRO 2007).

Transcrevemos, a seguir, o texto na forma original, ou seja, conforme foi elaborado pelo aluno, em sua produção inicial e na reescrita. 
Produção textual: o aluno escolheu o tema 1 para a sua produção.

Título: A pobreza no Brasil

O Brasil é um dos país que mais é atingido pela pobreza. Tem fatores que impedem que o Brasil seja mais desenvolvido.

O primeiro fato é o primeiro emprego, o mercado de trabalho maioria das vezes contratam pessoas com experiências, e com isso alguns jovens vão tentar uma vida mais fácil, que entra a questão da violência e da prostituição. E outros jovens correm atráz de fazer uma faculdade, uma pós-graduação para ter mais oportunidade no mercado do trabalho.

Mas também tem muitas famílias que saem na suas casas e cidades, e vão para uma vida melhor. Às vezes tem famílias que conseguem alcançar sonhos, mas as vezes e aos contrario só vão para sofrer.

Por isso que nós temos que nas eleições votar para candidatos que possam mudar essas situações e lutar por um mundo melhor para a nova geração que virá.

\section{Etapa da reescrita e análise linguística}

Depois de realizada a etapa de produção, recomendamos aos alunos a leitura de outros textos com a mesma temática que escolheram, levando em conta que "todos nós escrevemos mal se nos faltam ideias ou informações sobre o que falar." (ANTUNES, 2007, p. 47). Esta atividade tem o objetivo de ampliar o ponto de vista do aluno sobre o tema. Em seguida, apresentamos aos alunos o comando de reescrita.

Reescrita: Nesta etapa, a partir do texto selecionado, seriam relevantes algumas atividades de análise linguística, com o objetivo de que o aluno perceba "as várias formas de estruturar períodos e de ligá-los por meio de operadores argumentativos" (MENDONÇA, 2006, p. 214) e que os conectivos podem mudar o sentido do texto (Atividades 1, 2 e 3). Considerando a escola como lugar onde o aluno tem contato com a norma padrão, é de suma importância que se tenha contato com ela, não de maneira normativista, mas reflexiva. Isso é sugerido nas Atividades 4 e 5. 
Nota-se que o texto do estudante, após a etapa de reescrita, ainda apresenta poucos argumentos, isso pode ser atribuído à pouca leitura que ele possui. Em virtude disso, sugerimos atividade de leitura e refacção, com o objetivo de ampliar o leque argumentativo do aluno e a utilização dos modos de desenvolvimento estudados anteriormente. (Atividade 6)

Atividade 1: Note os conectivos em destaque no texto "e também", "mas", "portanto", "por isso". Qual a função deles no texto, respectivamente:

( )Para opor, dar consequência, concluir e para alternar ideias. ( )Para explicar ideias, dar consequência, opor e alternar ideias.

( )Para adicionar, opor, dar consequência e concluir ideias.

Atividade 2: O conectivo em destaque no segundo parágrafo poderia ser substituído por "todavia" sem que perdesse seu sentido? Justifique sua resposta.

Atividade 3: No texto há a repetição das palavras: pobreza, necessidades e cidades. Que palavras poderiam substituí-las?

Atividade 4: Observe a trecho abaixo. A seguir, reestruture-o adequando à norma padrão.

O Brasil é dos país que mais é atingido pela pobreza.

Atividade 5: Analise as palavras "qeu", "esqueçer", "batalha", "canditados". Com a ajuda de uma gramática e/ou dicionário, reescreva os trechos abaixo observando o emprego da norma padrão e procurando evitar a repetição de palavras e ideias. Não se esqueça de que, na língua escrita, as palavras não são grafadas conforme falamos.

a) Portanto com todos esses problemas tem muitas crianças tem qeu esqueçer seu tempo de crianças e batalha bem mais cedo para não passar necessidades.

b) Por isso que nós temos que nas eleições sabe para que votar, para que os canditados possam mudar essas situações, e lutar por um mundo melhor para a nova geração que virá.

Atividade 6: Agora você irá pesquisar em jornais e revistas textos que auxiliem na ampliação dos argumentos do texto trabalhado. Em seguida, analise como 
poderiam ser reescritos o segundo e o terceiro parágrafos, utilizando o modo de exemplificação e causa e consequência respectivamente.

Atividade 7: Etapa da reescrita: Avalie seu texto dissertativo-argumentativo.

Comando: Reúna-se com um colega e leia seu texto para ele. Ouça as sugestões do colega e, se as achar procedentes, altere o que for necessário.

Em seguida, observe se:

Você adequou o texto ao gênero (dissertativo-argumentativo).

Você se posiciona claramente sobre o tema.

Seu texto é coerente (unidade de sentido, organização).

Utilizou os conectivos que ligam ideias, parágrafos, ou seja, se seu texto é coeso.

O texto apresenta uma ideia principal, que resume seu ponto de vista.

A ideia principal é fundamentada no desenvolvimento com argumentos claros e consistentes.

Esses argumentos são bem desenvolvidos.

A conclusão realmente finaliza o texto.

A linguagem está de acordo com a variedade padrão e com o perfil do público leitor.

O texto apresenta título convidativo à leitura e, como um todo, é persuasivo.

Após refletir sobre isso, reescreva-o, fazendo as alterações necessárias.

Observe se você repetiu palavras e/ou ideias. Se a resposta for positiva, com a ajuda do dicionário, substitua estas palavras e ideias por palavras equivalentes. 


\title{
Texto do aluno reescrito:
}

\author{
Título: A pobreza no Brasil
}

O Brasil é dos país que mais é atingido pela pobreza. As favelas são os mais prejudicados pela falta de oportunidades. Nas cidades grandes é bem comum ver crianças no sinaleiro pedindo dinheiro ou vendendo alguma coisa para ter o que levar mais tarde para sua família, e também muitos jovens vendendo o seu corpo para ter algum dinheiro para se manter.

Muitos pensam que nas cidades grandes tem mais oportunidades e deixam suas famílias e suas cidades e vão tentar uma vida melhor, com algumas da tudo certo, mas nem todas conseguem o qeu querem e por isso passam mais necessidade ainda.

Portanto com todos esses problemas tem muitas crianças tem qeu esqueçer seu tempo de crianças e batalha bem mais cedo para não passar necessidades.

Por isso que nós temos que nas eleições sabe para que votar, para que os canditados possam mudar essas situações, e lutar por um mundo melhor para a nova geração que virá.

Observando a primeira versão da produção do aluno e a reescrita, nota-se que as atividades de análise linguística foram relevantes, pois a segunda versão ficou mais coerente e mais clara. $\mathrm{O}$ aluno reestruturou melhor o texto utilizando os conectivos. 